\title{
1 Physiochemical Properties and Food Application of Antimicrobial PLA
}

\section{Film}

3

4 Haiyan $\mathrm{Gao}^{\mathrm{a}}$, Xiangjun Fang ${ }^{\mathrm{a}}$, Hangjun Chen $^{\mathrm{a}}$, Yanhong Qin ${ }^{\mathrm{a}}$, Feifei Xu ${ }^{\mathrm{a}}$, Tony Z. Jin ${ }^{\mathrm{b}}$

$6{ }^{\text {a }}$ Institute of Food Science, Zhejiang Academy of Agricultural Sciences, Key Laboratory of

7 Fruits and Vegetables Postharvest and Processing Technology Research of Zhejiang Province,

8 Hangzhou, 310021, China

$9{ }^{\mathrm{b}}$ Eastern Regional Research Center, Agricultural Research Service, U.S. Department of

10 Agriculture, 600 E. Mermaid Lane, Wyndmoor, PA 19038, USA.

Authors for correspondence:

Jin: Tel.: 215-836-6904; Fax: 215-233-6559; E-mail: tony.jin@ars.usda.gov.

Gao: Tel: 0086-571-86404378; Fax: 0086-571-86406661; E-mail:spsghy@163.com. 


\section{Abstract}

Antimicrobial polylactic acid (PLA) films releasing allyl isothiocyanate (AIT) vapor were developed. The physicochemical properties and water vapor and gas permeability characteristics of the films were investigated, and the antimicrobial properties in vapor phase in food application were evaluated. The results reveal that the resultant antimicrobial (AM)

PLA films had less strength, less stiffness and more flexibility, a lower $\mathrm{O}_{2}$ and $\mathrm{CO}_{2}$ transmission rate, and a higher UV absorption rate than the pure PLA films. Avrami's equation showed the best fit with experimental release data $\left(\mathrm{R}^{2}>0.91\right)$ and indicated the release kinetics of AIT from the AM PLA film could be a combined mechanism of diffusion and first-order model. AM film treatment $(4 \times 8 \mathrm{~cm}$ film in 1 liter box $)$ significantly $(\mathrm{p}<0.05)$ inhibited total aerobic bacterial growth in fresh pak choi stored at 4 and $10^{\circ} \mathrm{C}$ for 15 days. The AM film treated pak choi had less color change and chlorophyll loss than the control samples during storage. The AM PLA film has the potential to be utilized for extending the shelf-life of various perishable food products.

Key words: antimicrobial packaging, essential oil, controlled release, polylactic acid, shelf

42 life, fresh produce.

Chemical compounds studied in this article

Allyl isothiocyanate (PubChem CID: 5971); Polylactic acid (PubChem CID: 3081262); 


\section{Introduction}

The demand for safe, minimally processed, ‘fresh' food products presents major challenges for the food-packaging industry to develop packaging materials which will be useful for maintaining the safety and quality of foods. The use of antimicrobial packaging is one of the approaches used to extend the shelf-life of minimally processed foods and reduce the risk of pathogen contamination. There is growing interest in the use of natural and renewable materials to produce antimicrobial food packaging. Plant extracts and biopolymers have been widely studied and reviewed for their food applications (Burt, 2004; Negi, 2012; Tharanathan, 2003).

Allyl isothiocyanate (AIT) is one of plant essential oils (EO). It is considered a natural antimicrobial agent for food preservation and is known for its volatility and strong antimicrobial activity. It is capable of inhibiting the growth of fungal and bacterial pathogens on plant seeds, fresh produce, bread, meat, and cheese (Lee et al. 2009; Li et al. 2007;

Nadarajah et al. 2005; Nielsen and Rios 2000). Like all essential oils, however, large amounts of AIT in the liquid phase must be directly applied on foods in order to achieve the desired antimicrobial effect. This, along with the volatility and strong, pungent odor associated with AIT, could negatively affect the organoleptic properties of food. Numerous studies have shown that AIT can be incorporated into biopolymers such as chitosan to make edible food coatings or packaging films in order to extend the shelf-life and reduce pathogenic contamination in various types of food, such as cantaloupe (Chen et al. 2012), ready-to-eat meat (Guo et al. 2015; 2014a; 2014b), shrimp (Guo et al 2013a; 2013b), and tomatoes (Jin and Gurtler 2012). Other alternative methods which could increase the 
antimicrobial efficacy of AIT in foods by using the lowest concentrations possible need to be developed. The use of essential oils by vapor contact has been proposed as an effective approach. Several studies have demonstrated that essential oils applied in vapor phase could be effective against foodborne pathogens and spoilage microorganisms at relatively lower concentrations than when applied in liquid phase, resulting in a less detrimental effect on the sensory attributes of food (Inouye et al. 2006; López et al. 2007; Nedorostova et al. 2009; Nielsen and Rios 2000; Suppakul et al. 2003; Tyagi and Malik 2011). Polylactic acid (PLA) polymers, which are derived from renewable resources such as corn, wood residues or other biomass, are of current interest not only because of the need to ultimately replace many petroleum-based polymers but also because of their potentially useful physical and mechanical characteristics. PLA polymers have been used in food packaging for a decade and recently PLA was also used as an antimicrobial carrier for antimicrobial packaging and coating. Jin and Zhang (2008) incorporated nisin into the PLA polymer and studied the retention of nisin activity and the antimicrobial effectiveness of the nisin/PLA film against foodborne pathogens in BHI Broth, orange juice, and liquid egg white. In another study, Jin and Niemira (2011) developed a PLA coating solution containing multiple antimicrobials to reduce $E$. coli $\mathrm{O} 157: \mathrm{H} 7$ or $S$. stanley populations on whole fresh apples. Glass jars or PEF bottles were coated with a mixture of polylactic acid (PLA) polymer and antimicrobial compounds and the efficacy of bottle coatings in inactivating foodborne pathogens and spoilage microorganisms in liquid egg white and fruit juice were investigated (Jin et al. 2014; Jin and Gurtler 2011). Ray et al. (2012) developed gaseous chlorine dioxide-releasing antimicrobial films by incorporating sodium chlorite and citric 
acid powder into PLA polymer. However, limited information is available regarding antimicrobial PLA films with AIT and their physiochemical and antimicrobial properties.

The objectives of this study were to 1) develop antimicrobial packaging materials incorporated with EOs; 2) evaluate their physicochemical properties; 3) and investigate their antimicrobial properties in vapor phase in food application. AIT was used as a model for EOs and pak choi (Brassica rapa L. ssp. chinensis) was used as a model for food application.

\section{Materials and Methods}

\subsection{Preparation of PLA films}

PLA films were prepared according to the solvent-casting method used by Jin and Zhang (2008) with some modifications. One gram of PLA resin (Natureworks, Minnetonka, MN, USA) was dispersed in $20 \mathrm{~mL}$ of methylene chloride (Fisher Scientific, Fairlawn, NJ, USA). This mixture was stirred by a magnetic bar until the polymer was totally dissolved. Predetermined amounts of tributyl citrate (TBC, Aladdin Industrial Corporation, Shanghai, China) and allyl isothiocyanate (AIT, Aldrich Chemical Co., Milwaukee, WI, USA) were added into the PLA solution and mixed. The solution was distributed into Teflon Petri dishes $10 \mathrm{~cm}$ in diameter and $1.5 \mathrm{~cm}$ deep (Performance Plastics, Wayne, NJ, USA). The methylene chloride was allowed to evaporate at $25^{\circ} \mathrm{C}$ under a chemical hood for $24 \mathrm{~h}$ to ensure no solvent residual in the films. After 24h, the films were peeled from the dishes, placed in a sealed bag, and stored at $4^{\circ} \mathrm{C}$ until time of use. The thickness of PLA film was determined using a spiral micrometer (Yiyu Mechanical Technology Co., Ltd., Shanghai, China). Measurements were made at 20 different spots and averaged. 


\subsection{Mechanical properties of PLA films}

Tensile strength at break and percentage elongation of PLA films were determined using TA.XT plus Texture Analyzer (Stable Micro system, Surrey, U.K.). The film size was $10 \mathrm{~mm} \times 150 \mathrm{~mm}$, and the crosshead speed was $20 \mathrm{~mm} / \mathrm{min}$. Other test parameters were set as follows: pre-test speed $1.0 \mathrm{~mm} / \mathrm{s}$, test speed $1.5 \mathrm{~mm} / \mathrm{s}$, and post-test speed $10.0 \mathrm{~mm} / \mathrm{s}$, trigger force $0.049 \mathrm{~N}$, distance $500 \mathrm{~mm}$. Three replicates were performed for each sample. from $20^{\circ} \mathrm{C}$ to $200^{\circ} \mathrm{C}$ at scanning rate of $10^{\circ} \mathrm{C} / \mathrm{min}$, then cooled from $200^{\circ} \mathrm{C}$ to $20^{\circ} \mathrm{C}$. Thermal

\subsection{Scanning Electron Microscopy}

The film samples were cut with surgical scissors into $3 \times 5 \mathrm{~mm}$ pieces and moun ted directly on specimen stubs with double-sided adhesive tape. The mounted film sa mples were vacuum-coated with gold sputtering layer. Digital images of topographical features of the film strips were collected using scanning electron microscopy (TM300 0, Hitachi Limited, Japan ) and Image $\mathbf{J}$ analysis software (Image $\mathbf{J}$, National Institute s of Health, USA).

\subsection{Differential Scanning Calorimetry (DSC)}

DSC was performed on the film samples using DSC 1 (Mettler Toledo, Schwerzenbach, Switzerland). The samples $(0.5 \mathrm{mg})$ were crimp-sealed in $40 \mu \mathrm{L}$ stainless steel pans. The instrument was purged with nitrogen. Thermal scanning was performed by heating the sample parameters were determined using the instrument software. 
2.5 Fourier transform infrared (FT-IR) spectroscopy and UV-VIS spectra of PLA films

Approximately $2 \mathrm{mg}$ of PLA films and $25 \mathrm{mg}$ of dry potassium bromide (KBr) crystal

were mixed and ground into small granules less than $2 \mu \mathrm{m}$ in diameter before the FT-IR analysis. Attenuated total reflection (ATR) FT-IR spectra were obtained using a Bruker Tensor 27 FTIR spectrometer (Bruker Optics, Billerica, MA, USA) equipped with an ATR accessory (ZnSe crystal, $\left.45^{\circ}\right)$ in the frequency range of 4000-400 $\mathrm{cm}^{-1}$. Spectra were collected with a resolution of $4 \mathrm{~cm}^{-1}$, and an average of 32 scans for each sample.

UV-visible spectra (UV-VIS) of PLA films were determined using a Cintra10e UV-VIS-NIR spectrophotometer (GBC Scientific Equipment Pty Ltd., Melbourne, Australia) in the wavelength range of $200-900 \mathrm{~nm}$.

\subsection{Gas and water vapor permeability}

Oxygen $\left(\mathrm{O}_{2}\right)$ and carbon dioxide $\left(\mathrm{CO}_{2}\right)$ permeability of film samples was measured using a Gas Permeability Tester (Lab BTY-B1 Model, Labthink, China). Film samples with a size of $120 \times 120 \mathrm{~mm}$ were prepared and conditioned a desiccator with anhydrous $\mathrm{CaCl}_{2}$ for $24 \mathrm{~h}$ before use. The test chamber was set at $23 \pm 2.0^{\circ} \mathrm{C}$ with relative humidity of $50 \pm 5 \%$. Three replicates were conducted for each sample.

Water vapor permeability (WVP) was measured using ASTM (1993) procedures. Briefly, deionized water was filled into round mouth conical plastic cups with a diameter of $60 \mathrm{~mm}$ and a height of $90 \mathrm{~mm}$. Then, films with a thickness of about $50 \mu \mathrm{m}$ were placed over the top of the cups and sealed on cup edge. There was a $4 \mathrm{~mm}$ distance between the film and water 

calculated by the following equation:

$$
\mathrm{WVP}=G / t A,
$$

where $G$ is the weight change in grams; $t$ is the duration of test in days and $A$ is the test area in $\mathrm{m}^{2}$. Six replicates were conducted for each WVP measurement and the results were averaged and reported as $\mathrm{g} \cdot \mathrm{m}^{-2} \cdot \mathrm{d}^{-1}$.

$$
\mathrm{R}=\left[1-\left(\mathrm{C}_{\mathrm{i}}-\mathrm{C}_{\mathrm{t}}\right) / \mathrm{C}_{\mathrm{i}}\right] \times 100 \%,
$$
where $\mathrm{C}_{\mathrm{i}}$ is initial concentration of AIT in film and $\mathrm{C}_{\mathrm{t}}$ is concentration of AIT in film at time

\subsection{Allyl-isothiocyanate (AIT) release kinetics}

Films were cut into $10 \mathrm{~mm} \times 30 \mathrm{~mm}$ pieces and placed in a petri dish $(70 \mathrm{~mm}$ in diameter and $35 \mathrm{~mm}$ in height). Each dish contained $0.5 \mathrm{~g}$ of film sample. The dishes were then sealed with caps and incubated at 4,10 , and $20^{\circ} \mathrm{C}$, respectively. After the set period of incubation dishes were withdrawn from the incubator and the film samples in the dishes were used for AIT analysis. The residual of AIT in films was determined by dissolving $0.2 \mathrm{~g}$ of PLA film samples in $50 \mathrm{ml}$ methylene chloride, and then the absorbance of the resulting solution was recorded using a spectrophotometer at $245 \mathrm{~nm}$. The readings were converted to the AIT concentrations referring to a predetermined standard curve. Triplicate experiments were conducted for each sample. The residual (R) of AIT in film after release was defined as shown below: 


\subsection{Food preparation, package, film treatment and storage}

Pak choi (Brassica rapa L. ssp. chinensis) was purchased from a local supermarket

(Hangzhou, China), transported within $30 \mathrm{~min}$ to the laboratory and allowed to equilibrate at 6- $8^{\circ} \mathrm{C}$ for $3 \mathrm{~h}$. Damaged and yellow colored leaves were discarded. Pak choi samples were washed with running tap water to remove any dirt. Approximately $80 \mathrm{~g}$ of pak choi were placed in a PET box $(125 \times 165 \times 64 \mathrm{~mm})$ with a $4 \times 8 \mathrm{~cm}^{2}$ antimicrobial PLA film sample on the inner side of the box lid, as shown in Figure 6. Pak choi samples placed in PET boxes without film samples served as controls. All samples were stored at 4 and $10^{\circ} \mathrm{C}$ for 15 days. The changes in microbial populations, color and chlorophyll contents in samples were determined at $0,3,6,9,12$, and $15 \mathrm{~d}$, according to the methods described below.

\subsubsection{Color determination}

The color of pak choi leaves was determined using a handheld portable Chroma Meter (HYGROLAB CR-400, Konica Minolta, NJ, USA). Prior to use, black and white standard tiles were used to calibrate the instrument using those that came with the instrument. Ten measurements were performed for each treatment and storage time. $L^{*}, a^{*}$, and $b^{*}$ values were recorded. The color changes during storage was represented as $\Delta E$, and calculated using the following equations:

$$
\Delta E=\sqrt{\left(a^{*}-a_{0}^{*}\right)^{2}+\left(b^{*}-b_{0}^{*}\right)^{2}+\left(L^{*}-L_{0}^{*}\right)^{2}}
$$

where $L_{0}^{*}, a_{0} *$, and $b_{0}^{*}$ are the control values at day 0 , and $L^{*}, a^{*}$, and $b^{*}$ are the values for the treated samples at each storage time. 


\subsubsection{Chlorophyll measurement}

Chlorophyll contents in pak choi leaves were estimated nondestructively using a portable chlorophyll meter (SPAD-520, Minolta Co. Ltd, Tokyo, Japan). Three leaves were randomly selected from each box and four readings per leaf were recorded. The results were reported as milligram per gram of fresh weight.

\subsection{Microbiological analysis}

The total aerobic bacterial load on pak choi samples was evaluated using the standard plate count method. Total plate count agar (PCA, Shanghai Dingguo Biotechnology Co. China) was used to determine total aerobic bacterial counts. A $25 \mathrm{~g}$ sample from each box was diluted in $225 \mathrm{ml}$ of sterile distilled water and homogenized using a sterilized kitchen blender homogenizer at $8,000 \mathrm{rpm}$ for $2 \mathrm{~min}$. Each sample was serially diluted and $1 \mathrm{~mL}$ of each dilution was transferred to a sterile petri dish. About $20 \mathrm{~mL}$ of sterile total plate count counted and multiplied by the appropriate dilution factor to obtain total plate counts.

\subsection{Statistical analysis}

The experiments were triplicate and all data were expressed as means \pm standard errors of triplicate measurements and analyzed by SAS software (SAS Institute, Cary, NC, USA). 
between control and treated samples. Significant differences were defined at $p<0.05$.

\section{Results and Discussion}

\subsection{Physical Properties of Films}

3.1.1 Thermal Properties. The DSC thermograms of the PLA films are shown in Figure 1.

The glass transition and the crystalline status of test specimens are summarized in Table 1.

The glass transition temperature ( $\mathrm{Tg}$ ) and melting temperature ( $\mathrm{Tm}$ ) of PLA were found to be about 60 and $166^{\circ} \mathrm{C}$, respectively. The addition of $\mathrm{TBC}$ reduced the $\mathrm{Tg}$ and $\mathrm{Tm}$ of the resultant films to 40.66 and 162.74 at $7.5 \%$ TBC, respectively. However, increasing the concentrations of $\mathrm{TBC}$ to $10 \%$ resulted in an increase in $\mathrm{Tg}$, therefore, the formula with $7.5 \%$ TBC was used for incorporation of AIT. The inclusion of AIT further increased the Tg, and decreased the Tm. The peak of each sample broadened toward lower temperatures, and the onset of the transition also moved toward lower temperature ranges. Correspondingly, the $\mathrm{Tg}$ for each of the blends was also shifted to lower temperatures. The lowering of the $\mathrm{Tg}$ and $\mathrm{Tm}$ of the AM PLA films could be attributed to the presence of TBC (Table 1), which reduced the macromolecular interactions.

3.1.2 Mechanical Properties. The mechanical properties of PLA films are presented in Table

2. Increased TBC concentrations significantly reduced the tensile strength (TS) of the PLA vs $7.5 \% \mathrm{TBC}$ ). In contrast, increased TBC concentrations significantly increased the 
elongation at break with a maximum value reached when TBC concentrations were at $7.5 \%$

245

246

247 (7.5\% TBC). Similar to TS, the addition of AIT to 7.5\% TBC had no significant effect on the elongation of the films (TBC+AIT vs 7.5\% TBC). The effect of TBC concentrations on the elongation is corresponded to the effect on $\mathrm{Tg}$, where the lowest $\mathrm{Tg}$ was found at $7.5 \% \mathrm{TBC}$ (Table 1). Therefore the resultant AM PLA films had less strength, less stiffness and more flexibility, compared with pure PLA films. TBC is a plasticizer often used in plastic industries. The inclusion of TBC into PLA altered the brittle nature of PLA by increasing its flexibility, and thus the PLA/TBC blends were tougher than pure PLA specimens, which was expected because of the softening effect.

3.1.3 Permeability Characteristics. Table 2 also shows the water vapor, and $\mathrm{O}_{2}$ and $\mathrm{CO}_{2}$ transmission rates of PLA films. The water vapor transmission rate was significantly increased as TBC concentrations increased. The AM PLA film with 7.5\% TBC and AIT had lower WVTR value than pure PLA film, although the difference was not significant $(\mathrm{p}>0.05)$.

The increase in TBC concentrations resulted in lower oxygen and carbon dioxide transmission rates and addition of AIT further reduced oxygen permeability. The AM PLA films with TBC and AIT had significantly $(\mathrm{p}<0.05)$ lower $\mathrm{O}_{2}$ and $\mathrm{CO}_{2}$ transmission rates than the pure PLA films.

Based on the results of the thermal and mechanical properties and gas permeability characteristics, AM PLA film with 7.5\% TBC and 5\% AIT (TBC+AIT) was selected for further evaluation in comparison with pure PLA film. 

(cross section) are shown in Figure 2. A homogeneous, smooth morphology was observed for the blends of PLA+TBC+AIT (Figure 2A), indicating that three compounds were highly compatible. Micro pores could be clearly observed on the pure PLA film (Figure 2B). The pores were possibly created by the mixing and separation of air in the solution during stirring and solvent evaporation, respectively, resulting in the formation of a heterogeneous structure transmission rates than the pure PLA films as presented in Table 2.

3.1.5 Fourier Transform Infrared Spectroscopy. Figure 3 showed the FTIR spectra of the 
AIT and TBC shifted the peak to a slightly longer wavelength and centered at about $240 \mathrm{~nm}$.

289

290

291

292

293

294

295

296

297

298

299

300

301

302

303

304

305

306

307

308

309

The AM PLA film had a significantly higher UV absorption rate $(3.5 \mathrm{X})$ than the pure PLA film.

\subsection{AIT Release Kinetics}

The release of AIT from the films were determined at 4,10 and $20^{\circ} \mathrm{C}$. These temperatures were representative of refrigeration temperature, temperature abuse, and room temperature, respectively. Figure 5 shows the release profiles of AIT up to 16 days. Avrami's equation was applied to demonstrate the release kinetics of AIT from the AM PLA film. This model is described by the following equation:

$R=\exp \left[-(\mathrm{kt})^{\mathrm{n}}\right]$

where, $R$ is the residual of AIT at time $t ; k$ is the release rate constant and $n$ is a parameter representing the release mechanism. The equation can be rewritten by double logarithm as follows:

$\ln (-\ln R)=n \ln k+n \ln t$

A linear plot of $\ln (-\ln R)$ versus $\ln t$ from data in Figure 5 allows to determine the release rate constant $k$ (intercept) and release parameter $n$ (slope) that are listed in Table 3 .

Our results clearly showed that the release kinetics of AIT depend on temperature, as the release rate constant $k$ values increased as the temperature increased. As shown in Table $3, n$ values were found in the range from 0.64 to 0.90 . The $n$ value characterizes the release mechanism that describes the shape of a release time-course. Theoretically, the parameter $n=$ 0.54 indicates a diffusive release and $n=1$ a first-order release kinetics (Shiga et al 2001). 
Hence, the release kinetics of AIT from the AM PLA film could be a combined mechanism of diffusion and first-order model. The obtained results were successfully fitted with the Avrami's equation, as the correlation coefficient $\mathrm{R}^{2}$ for each test temperature exceeds 0.91 .

\subsection{Food Application of AM PLA Film}

Pak choi was used as a model for fresh produce. A piece of AM PLA film was stuck on the inner side of the lid of the PET container before it was closed, as highlighted in Figure 6. Microbial growth and quality changes in pak choi were monitored during storage at 4 and $10^{\circ} \mathrm{C}$. Table 4 summarizes the results of microbial growth and quality changes in pak choi during storage.

3.3.1 Microbial Growth. Populations of mesophilic aerobic bacteria of up to $8 \log 10 \mathrm{cfu} / \mathrm{g}$ were commonly reported on fresh leafy vegetables, which including Pseudomonas, Erwinia, Xanthomonas, and E. coli (Barth et al. 2009; FAO 2008). Therefore, total plate count (TPC) method was used in the present study to determine the antimicrobial efficacy of the films. Bacterial populations increased during storage for all samples (Table 4). Samples with AM PLA film treatment had significantly $(\mathrm{p}<0.05)$ lower cell populations than controls regardless of storage temperature after 3 days. After storage for $15 \mathrm{~d}$, total plate counts in pak choi samples subject to film treatment at 4 and $10^{\circ} \mathrm{C}$ were 7.18 and $8.15 \log \mathrm{CFU} / \mathrm{g}$, and 9.58 and $10.34 \log \mathrm{CFU} / \mathrm{g}$ in the controls at 4 and $10^{\circ} \mathrm{C}$, respectively. Pak choi samples subject to film treatment had lower bacterial populations over the $15 \mathrm{~d}$ storage period compared to the 
controls, regardless of storage temperature. The AM PLA film was effective in inhibiting microbial growth at both temperatures.

3.3.2 Color Change. Color changes during storage occurred for all samples (Table 4). The total color difference $\Delta \mathrm{E}$ was used to evaluate the degree of changes compared to original colors. In general, control samples stored at $10^{\circ} \mathrm{C}$ had the greatest color change during storage, and the rest had statistically similar color changes. After storage for $15 \mathrm{~d}$, the $\Delta \mathrm{E}$ values in pak choi samples subject to film treatment at 4 and $10^{\circ} \mathrm{C}$ were 4.68 and 7.77 , and 9.30 and 15.8 in the controls at 4 and $10^{\circ} \mathrm{C}$, respectively. The AM PLA film improved the color stability of fresh pak choi during storage at both storagetemperatures.

\subsubsection{Chlorophyll Content Change. The chlorophyll contents in AM PLA film treated} samples were well maintained for 9d regardless of storage temperature, after which they gradually decreased, while the chlorophyll contents in control samples started to decrease after 6 days storage, especially for those stored at $10^{\circ} \mathrm{C}$ (Table 4). After 15 days, the chlorophyll contents for all samples were not statistically different except for the control samples stored at $10^{\circ} \mathrm{C}(\mathrm{CK}-10 \mathrm{C})$. These results were similar to the total color difference $\Delta \mathrm{E}$. This is probably because the degradation of chlorophyll resulted in the yellowing of pak choi samples, leading to a greater total color change compared with the samples before storage.

The $\mathrm{b}$ value (yellowness) for control samples stored at $10^{\circ} \mathrm{C}(\mathrm{CK}-10 \mathrm{C})$ was much higher than for the other samples (data not shown). 


\section{Discussion}

Microbial contamination can occur at almost any point in the food production process

before packaging. Conventional packaging does not stop the growth of pathogens and spoilage microorganisms on food after packaging and before consumption. Therefore, antimicrobial packaging provides the final hurdle to prevent microbial growth and food deterioration. In this study, the AM PLA film significantly inhibited the growth of total aerobic bacteria in pak choi over 15 days at 4 and $10^{\circ} \mathrm{C}$ compared to controls. The film treated samples also had the least color change and chlorophyll loss (Table 4). The typical pungent odor of AIT was not noticed on pak choi after storage. This may be due to the small size of the AM PLA films used in this study as well as the low AIT concentrations 
properties are important for their applications. In this study, the resultant AM PLA films had less strength, less stiffness and more flexibility, compared with pure PLA films (Table 2) due to the plasticizing effect of TBC and AIT, which suggests that the AM PLA film is similar or superior to pure PLA film that is used as regular packaging material.

Food deterioration during storage can be microbiological and biochemical. Food lipids are food components that are very susceptible to oxidation processes. Oxidation reactions are one of the major causes of food deterioration during the manufacturing, storage, distribution and final preparation of foods (Johnson and Decker 2015). The oxidation of food products can not only reduce their shelf life, but also can be hazardous to human health. Lipid oxidation is caused by the presence of oxygen in the package and promoters such as UV light exposure. Therefore, oxygen and UV light barriers are needed for food, particularly those with high amounts of lipids.

The AM PLA films had similar water vapor but significantly $(\mathrm{p}<0.05)$ lower $\mathrm{O}_{2}$ and $\mathrm{CO}_{2}$ transmission rates than the pure PLA films. In other word, the AM PLA film had better gas barrier than pure PLA film (Table 2). A decrease in $\mathrm{O}_{2}$ permeability of packaging film would allow for the blockage of oxygen penetration into the food product, thus preventing food oxidation and maintaining product quality.

UV light is one of the oxidation promoters. The prolonged exposure of packaged food to daylight or artificial light during transportation, storage and display in retail stores could cause food oxidation. As shown in Figure 4, the AM PLA film had nearly three times higher UV absorbance than the pure PLA film and provides stronger UV protection for packaged foods. In addition, the AM film had a similar transparent appearance to the pure PLA film 
397

(Figure 6). These optical properties of the AM PLA film are very beneficial for food applications when the films are used as stand-alone packaging.

Because a solvent-casting method was used for making films in the present study, evaporation of the solvent may cause the loss of AIT in the films. Therefore, the determination of release kinetics and residual of AIT is important. Avrami's equation has been used extensively for release kinetics description. This equation was used to correlate the release characteristics of essential oils from $\beta$-cyclodextrin (Wang et al. 2011; Yang et al. 2015), carbon dioxide from $\alpha$-cyclodextrin (Neoh et al., 2006), and allyl isothiocyanate from $\alpha$ - and $\beta$ - cyclodextrin ( $\mathrm{Li}$ et al. 2007). Controlled release is important in research and development of encapsulation technology (Kytariolos et al. 2010). The results in this study showed that encapsulation of AIT in PLA film could efficiently control its release under defined temperature conditions (Figure 5). As presented in Table 3, the release rate constant $k$ values increased with increasing temperature. Increased concentrations of AIT would be released from the films at higher temperatures than at lower temperatures. This would enhance the antimicrobial effect of AIT since the rate of microbial growth is faster at higher temperatures.

AIT or other volatile EOs can be encapsulated in other polymers similar to the method used in this study. However, the special characteristics of PLA, such as generally recognized as safe (GRAS) status, biodegradability and being a bio-resource put PLA in a unique position for food applications. Similarly, the food applications of PLA films can be extended to other ready-to-eat (RTE) foods, minimally processed foods, raw foods or semi-processed foods for which microbial contamination is a major concern and a longer shelf-life is required. 
Nevertheless, further studies are needed for their applications. This is a preliminary study that provides a starting point, and further research will be required to evaluate these physiochemical and antimicrobial properties for the AM PLA films made with extrusion technology so that the antimicrobial packaging materials could be scaled up to a production scale.

\section{Conclusions}

Our preliminary study shows that the developed AM PLA films with AIT and TBC had similar or superior mechanical properties and gas permeability characteristics compared to pure PLA films. The AM PLA film treatment significantly inhibited bacterial growth in fresh pak choi at both 4 and $10^{\circ} \mathrm{C}$ for 15 days and maintained the quality with minimal color change and chlorophyll loss. The release behavior of AIT from PLA film was well simulated by Avrami's equation. The combination of biosourced/biodegradable food packaging materials and natural antimicrobials provides additional benefits for environmental protection and acceptance by consumers. The results from the present study provide the base for further studies. The AM PLA film has the potential to be utilized for extending the shelf life of a broad range of perishable food products.

\section{Acknowledgement}

This research was supported by International Science \& Technology Cooperation Program of China, No. 2013DFA31450 and National science \& Technology Pillar Program of China, No. 2015BAD16B00 and was conducted in collaboration between Zhejiang Academy of Agricultural Science and USDA-ARS under USDA Cooperative Research Agreement (\# 
58-3K95-3-1631-M-F). Mention of trade names or commercial products in this article is solely for the purpose of providing specific information and does not imply recommendation or endorsement by the U.S. Department of Agriculture. USDA is an equal opportunity employer.

\section{References}

ASTM. 1993 Standard test methods for water vapor transmission of materials. Designation: E96-93, 701-708.

Barth, M., Hankinson, T.R., Zhuang, H., and Frederick Breidt, F. 2009. Microbiological Spoilage of Fruits and Vegetables. W.H. Sperber, M.P. Doyle (eds.). Compendium of the Microbiological Spoilage of Foods and Beverages, Food Microbiology and Food Safety. Springer Science+Business Media. Pp135-183.

Burt, S. 2004. Essential oils: Their antibacterial properties and potential applications in foods - A review. International Journal of Food Microbiology 94, 223-253.

Chen, W., Jin, T.Z., Gurtler, J.B., Geveke, D.J., Fan, X. 2012. Inactivation of Salmonella on whole cantaloupe by application of an antimicrobial coating containing chitosan and allyl isothiocyanate. International Journal of Food Microbiology 155, 165-170.

FAO/WHO. 2008. Microbiological hazards in fresh leafy vegetables and herbs. http://www.who.int/foodsafety/publications/micro/mra_fruitveges/en/ viewed November $8,2016$.

Guo, M., Jin, T.Z., Scullen, O.J., Sommers, C.H. 2013a. Effects of antimicrobial coatings and cryogenic freezing on survival and growth of Listeria innocua on frozen ready-to-eat shrimp during thawing. Journal of Food Science 78, M1195-M1200. 
Guo, M., Jin, T.Z., Wang, L., Scullen, O.J., Sommers, C.H. 2014a. Antimicrobial films and coatings for inactivation of Listeria innocua on ready-to-eat deli turkey meat. Food Control 40, 64-70.

Guo, M., Jin, T.Z., Yadav, M.P., Yang, R. 2015. Antimicrobial property and microstructure of micro-emulsion edible composite films against Listeria. International Journal of Food Microbiology 208, 58-64.

Guo, M., Jin, T.Z., Yang, R. 2014b. Antimicrobial polylactic acid packaging films against Listeria and Salmonella in culture medium and on ready-to-eat meat. Food and Bioprocess Technology 7, 3293-3307.

Guo, M., Jin, T.Z., Yang, R., Antenucci, R., Mills, B., Cassidy, J., Scullen, O.J., Sites, J.E., Rajkowski, K.T., Sommers, C.H. 2013b. Inactivation of natural microflora and inoculated Listeria innocua on whole raw shrimp by ozonated water, antimicrobial coatings, and cryogenic freezing. Food Control 34, 24-30.

Inouye, S., Takizawa, T., Yamaguchi, H. 2001. Antibacterial activity of essential oils and their major constituents against respiratory tract pathogens by gaseous contact. Journal of Antimicrobial Chemotherapy 47, 565-573.

Inouye, S., Uchida, K., Maruyama, N., Yamaguchi, H., Abe, S. 2006. A novel method to estimate the contribution of the vapor activity of essential oils in agar diffusion assay. Japanese Journal of Medical Mycology 47, 91-98.

Jin, T.Z., Guo, M.,Yang, R. 2014. Combination of pulsed electric field processing and antimicrobial bottle for extending microbiological shelf-life of pomegranate juice. Innovative Food Science and Emerging Technologies 26, 153-158. 
487

488

489

490

491

492

493

494

495

496

497

498

499

500

501

502

503

504

505

506

507

508

Jin, T., Gurtler, J.B. 2012. Inactivation of Salmonella on tomato stem scars by edible chitosan and organic acid coatings. Journal of Food Protection 75, 1368-1372.

Jin, T., Gurtler, J.B. 2011. Inactivation of Salmonella in liquid egg albumen by antimicrobial bottle coatings infused with allyl isothiocyanate, nisin and zinc oxide nanoparticles. Journal of Applied Microbiology 110, 704 - 712.

Jin, T.Z., Gurtler, J.B., Li, S-Q. 2013. Development of antimicrobial coatings for improving the microbiological safety and quality of shell eggs. Journal of Food Protection 76, $779-785$.

Jin, T., Niemira, B. 2011. Application of polylactic acid coating with antimicrobials in reduction of Escherichia coli O157:H7 and Salmonella stanley on apples. Journal of Food Science 76, M184-M188.

Jin, T., Zhang, H. 2008. Biodegradable polylactic acid polymer with nisin for use in antimicrobial food packaging. Journal of Food Science 73, M127-M134.

Johnson, D.R., Decker, E.A. 2015. The role of oxygen in lipid oxidation reactions: A review. Annual Review of Food Science and Technology 6, 171-190.

Kytariolos, J., Dokoumetzidis, A., Macheras, P. 2010. Power Law IVIVC: An application of fractional kinetics for drug release and absorption. European Journal of Pharmaceutical Sciences 41, 299-304.

Lee, G-H., Kang, H-A., Kim, K-H., Shin, M-G. 2009. Microencapsulation effects of allyl isothiocyanate with modified starch using fluidized bed processing. Food Science and Biotechnology 18, 1071-1075.

Li, X., Jin, Z., Wang, J. 2007. Complexation of allyl isothiocyanate by $\alpha$ - and $\beta$-cyclodextrin 
and its controlled release characteristics. Food Chemistry 103, 461-466.

510

Liu, L. S.; Jin, T. Z.; Finkenstadt, V. T.; Liu, C.-K. Liu; Cooke, P. H. Cooke; Coffin, D. R.; Hicks, K. B.; Samer, C. 2009. Antimicrobial packaging materials from poly(lactic acid) incorporated with pectin-Nisaplin microparticles. Journal of the Balkan Tribological Association 3(3), 221-230.

López, P., Sánchez, C., Batlle, R., Nerín, C. 2007. Vapor-phase activities of cinnamon, thyme, and oregano essential oils and key constituents against foodborne microorganisms. Journal of Agricultural and Food Chemistry 55, 4348-4356.

Nadarajah, D., Han, J.H., Holley, R.A. 2005. Use of mustard flour to inactivate Escherichia coli $\mathrm{O} 157: \mathrm{H7}$ in ground beef under nitrogen flushed packaging. International Journal of Food Microbiology 99, 257-267.

Nedorostova, L., Kloucek, P., Kokoska, L., Stolcova, M., Pulkrabek, J. 2009. Antimicrobial properties of selected essential oils in vapour phase against foodborne bacteria Food Control 20, 157-160.

Negi, P.S. 2012. Plant extracts for the control of bacterial growth: Efficacy, stability and safety issues for food application. International Journal of Food Microbiology 156, 7-17.

Neoh, T-L., Yoshii, H., Furuta, T. 2006. Encapsulation and release characteristics of carbon dioxide in $\alpha$-cyclodextrin. Journal of Inclusion Phenomena and Macrocyclic Chemistry $56,125-133$.

Nielsen, P.V., Rios, R. 2000. Inhibition of fungal growth on bread by volatile components from spices and herbs, and the possible application in active packaging, with special 
emphasis on mustard essential oil. International Journal of Food Microbiology 60, 219-229.

532

Ray, S., Jin, T., Fan, X., Liu, L., Yam, K.L. 2013. Development of chlorine dioxide releasing film and its application in decontaminating fresh produce. Journal of Food Science 78, M276 - M284.

Shiga, H., Yoshii, H., Nishiyama, T., Furuta, T., Forssele, P., Poutanen, K., Linko, P. 2001. Flavor encapsulation and release characteristics of spray-dried powder by the blended encapsulant of cyclodextrin and gum arabic. Drying Technology 19, 1385-1395.

Suppakul, P., Miltz, J., Sonneveld, K., Bigger, S.W. 2003. Antimicrobial properties of basil and its possible application in food packaging. Journal of Agricultural and Food

$$
\text { Chemistry 51, 3197-3207. }
$$

Tharanathan, R.N. 2003. Biodegradable films and composite coatings: Past, present, and future. Trends in Food Science and Technology 14, 71-78.

Tyagi, A.K., Malik, A. 2011. Antimicrobial potential and chemical composition of Mentha piperita oil in liquid and vapour phase against food spoiling microorganisms. Food Control 22, 1707-1714

Wang, T., Li, B., Si, H., Lin, L., Chen, L. 2011. Release characteristics and antibacterial activity of solid state eugenol/ $\beta$-cyclodextrin inclusion complex. Journal of Inclusion Phenomena and Macrocyclic Chemistry 71, 207-213.

Yang, Z., Xiao, Z., Ji, H. 2015. Solid inclusion complex of terpinen-4-ol/ $\beta$-cyclodextrin: Kinetic release, mechanism and its antibacterial activity. Flavour and Fragrance Journal $30,179-187$. 
554

\begin{tabular}{|c|c|c|c|c|c|}
\hline \multirow[b]{2}{*}{ Film sample } & \multirow[b]{2}{*}{$T_{\mathrm{g}}\left({ }^{\circ} \mathrm{C}\right)$} & \multicolumn{2}{|l|}{ exotherm } & \multicolumn{2}{|c|}{ endotherm } \\
\hline & & $T_{\mathrm{cc}}\left({ }^{\circ} \mathrm{C}\right)$ & $\Delta H_{\mathrm{cc}}(\mathrm{J} / \mathrm{g})$ & $T_{\mathrm{m}}\left({ }^{\circ} \mathrm{C}\right)$ & $\Delta H_{\mathrm{m}}(\mathrm{J} / \mathrm{g})$ \\
\hline $0 \% \mathrm{TBC}$ & 59.66 & 131.67 & -7.35 & 168.44 & 29.35 \\
\hline $2.5 \% \mathrm{TBC}$ & 51.56 & 123.33 & -15.85 & 166.42 & 31.49 \\
\hline $5 \% \mathrm{TBC}$ & 51.38 & 122.64 & -11.91 & 165.08 & 29.64 \\
\hline $7.5 \% \mathrm{TBC}$ & 40.66 & 113.33 & -19.26 & 162.74 & 38.78 \\
\hline $10 \% \mathrm{TBC}$ & 44.93 & 116.81 & -13.38 & 162.74 & 26.08 \\
\hline $7.5 \% \mathrm{TBC}+5 \% \mathrm{AIT}$ & 50.06 & 126.53 & -15.78 & 160.77 & 31.88 \\
\hline
\end{tabular}

555

556 
557 Table 2 Mechanical and barrier properties of PLA films

558

\begin{tabular}{lllllll}
\hline & $0 \% \mathrm{TBC}$ & $2.5 \% \mathrm{TBC}$ & $5 \% \mathrm{TBC}$ & $7.5 \% \mathrm{TBC}$ & $10 \% \mathrm{TBC}$ & TBC+AIT* \\
\hline $\mathrm{TS}$ & $42.13 \pm 3.8 \mathrm{a}$ & $32.60 \pm 1.4 \mathrm{~b}$ & $29.73 \pm 0.1 \mathrm{bc}$ & $27.75 \pm 1.6 \mathrm{c}$ & $22.25 \pm 0.8 \mathrm{~d}$ & $22.65 \pm 1.3 \mathrm{c}$ \\
$\mathrm{EB}$ & $1.65 \pm 0.17 \mathrm{~d}$ & $38.50 \pm 7.10 \mathrm{c}$ & $90.38 \pm 1.32 \mathrm{~b}$ & $109.3 \pm 17.35 \mathrm{a}$ & $82.26 \pm 3.94 \mathrm{~b}$ & $113.3 \pm 7.93 \mathrm{a}$ \\
\hline $\mathrm{WV}$ & $177.7 \pm 4.5 \mathrm{~b}$ & $182.2 \pm 11.6 \mathrm{~b}$ & $204.6 \pm 9.3 \mathrm{ab}$ & $206.1 \pm 13.8 \mathrm{a}$ & $218.0 \pm 1.8 \mathrm{a}$ & $166.6 \pm 8.3 \mathrm{~b}$ \\
& & & & & & \\
$\mathrm{O}_{2}$ & $386.8 \pm 14.6 \mathrm{a}$ & $373.3 \pm 14.1 \mathrm{a}$ & $366.5 \pm 22.5 \mathrm{a}$ & $326.1 \pm 20.8 \mathrm{~b}$ & $309.8 \pm 26.5 \mathrm{~b}$ & $198.3 \pm 23.6 \mathrm{c}$ \\
$\mathrm{CO}_{2}$ & $3664 \pm 56 \mathrm{a}$ & $1038 \pm 106 \mathrm{~b}$ & $860 \pm 122 \mathrm{c}$ & $948 \pm 92 \mathrm{bc}$ & $880 \pm 98 \mathrm{c}$ & $459 \pm 57 \mathrm{~d}$ \\
\hline
\end{tabular}

559

560 TS: tensile strength, MPa; EB: elongation at break, \%; WV: water vapor permeability,

$561 \mathrm{~g} \cdot \mathrm{m}^{-2} \cdot \mathrm{d}^{-1} ; \mathrm{O}_{2}$ : oxygen permeability, $\mathrm{ml} \cdot \mathrm{m}^{-2} \cdot \mathrm{d}^{-1} ; \mathrm{CO}_{2}$ : carbon dioxide permeability,

$562 \mathrm{ml} \cdot \mathrm{m}^{-2} \cdot \mathrm{d}^{-1}$. Data shows the means \pm standard deviation. Different letters represented a

563 significant difference within the same row $(p<0.05)$.

$564 *$ The AM PLA film contained 7.5\% TBC and 5\% AIT.

565

566 
567 Table 3 Release kinetic parameters of AIT from AM PLA film*

568

\begin{tabular}{lllll}
\hline Temperature & $n$ & $k$ & Regression Eq. & $\mathrm{R}^{2}$ \\
\hline $4^{\circ} \mathrm{C}$ & 0.6439 & 0.0571 & $\mathrm{y}=0.6439 \mathrm{x}-1.8434$ & 0.9390 \\
$10^{\circ} \mathrm{C}$ & 0.9042 & 0.0960 & $\mathrm{y}=0.9042 \mathrm{x}-2.1191$ & 0.9478 \\
$20^{\circ} \mathrm{C}$ & 0.7883 & 0.1947 & $\mathrm{y}=0.7883 \mathrm{x}-1.2899$ & 0.9179 \\
\hline
\end{tabular}

569

570

*AM PLA film contained $7.5 \%$ TBC and 5\% AIT.

571 


\begin{tabular}{|c|c|c|c|c|c|c|c|}
\hline & \multirow[t]{2}{*}{ Treatment } & \multicolumn{6}{|c|}{ Storage time (day) } \\
\hline & & 0 & 3 & 6 & 9 & 12 & 15 \\
\hline \multirow[t]{4}{*}{$\mathrm{TPC}$} & CK-10C & $6.28 \pm 0.13 \mathrm{a}$ & $6.40 \pm 0.17 a$ & $6.57 \pm 0.08 b$ & $7.41 \pm 0.01 b$ & $9.37 \pm 0.14 \mathrm{a}$ & $10.34 \pm 0.02 \mathrm{a}$ \\
\hline & FT-10C & $6.28 \pm 0.13 a$ & $5.69 \pm 0.12 b$ & $5.55 \pm 0.11 \mathrm{~d}$ & $7.62 \pm 0.21 \mathrm{ab}$ & $7.53 \pm 0.08 c$ & $8.15 \pm 0.04 c$ \\
\hline & $\mathrm{CK}-4 \mathrm{C}$ & $6.28 \pm 0.13 a$ & $6.51 \pm 0.07 a$ & $6.98 \pm 0.08 \mathrm{a}$ & $7.78 \pm 0.05 \mathrm{a}$ & $8.40 \pm 0.06 \mathrm{~b}$ & $9.58 \pm 0.12 b$ \\
\hline & FT-4C & $6.28 \pm 0.13 \mathrm{a}$ & $5.53 \pm 0.14 b$ & $6.18 \pm 0.07 c$ & $6.89 \pm 0.12 c$ & $7.12 \pm 0.02 \mathrm{~d}$ & $7.18 \pm 0.06 \mathrm{~d}$ \\
\hline \multirow[t]{4}{*}{$\Delta \mathrm{E}$} & CK-10C & 0 & $11.20 \pm 4.7 \mathrm{a}$ & $9.40 \pm 3.79 \mathrm{a}$ & $16.48 \pm 4.81 \mathrm{a}$ & $11.97 \pm 3.67 \mathrm{a}$ & $15.80 \pm 5.18 \mathrm{a}$ \\
\hline & FT-10C & 0 & $3.51 \pm 1.20 \mathrm{~b}$ & $5.23 \pm 2.37 \mathrm{ab}$ & $6.07 \pm 2.99 b$ & $6.11 \pm 2.74 b$ & $7.77 \pm 5.30 \mathrm{bc}$ \\
\hline & $\mathrm{CK}-4 \mathrm{C}$ & 0 & $4.28 \pm 2.60 \mathrm{~b}$ & $6.43 \pm 3.57 \mathrm{ab}$ & $8.50 \pm 1.39 b$ & $8.14 \pm 4.41 \mathrm{ab}$ & $9.30 \pm 2.93 b$ \\
\hline & FT-4C & 0 & $3.77 \pm 1.48 b$ & $4.05 \pm 2.55 b$ & $6.50 \pm 4.15 b$ & $6.81 \pm 2.12 b$ & $4.68 \pm 1.48 c$ \\
\hline \multirow[t]{4}{*}{$\mathrm{CHL}$} & $\mathrm{CK}-10 \mathrm{C}$ & $0.56 \pm 0.04 \mathrm{a}$ & $0.51 \pm 0.11 \mathrm{a}$ & $0.48 \pm 0.04 \mathrm{a}$ & $0.41 \pm 0.01 \mathrm{~d}$ & $0.27 \pm 0.01 \mathrm{c}$ & $0.23 \pm 0.01 b$ \\
\hline & FT-10C & $0.56 \pm 0.04 a$ & $0.55 \pm 0.01 \mathrm{a}$ & $0.52 \pm 0.02 \mathrm{a}$ & $0.54 \pm 0.01 b$ & $0.36 \pm 0.01 b$ & $0.37 \pm 0.03 \mathrm{a}$ \\
\hline & $\mathrm{CK}-4 \mathrm{C}$ & $0.56 \pm 0.04 a$ & $0.51 \pm 0.04 a$ & $0.48 \pm 0.11 \mathrm{a}$ & $0.47 \pm 0.02 \mathrm{c}$ & $0.43 \pm 0.02 \mathrm{a}$ & $0.38 \pm 0.01 \mathrm{a}$ \\
\hline & FT-4C & $0.56 \pm 0.04 a$ & $0.51 \pm 0.05 a$ & $0.57 \pm 0.09 a$ & $0.60 \pm 0.02 \mathrm{a}$ & $0.47 \pm 0.03 a$ & $0.39 \pm 0.01 \mathrm{a}$ \\
\hline
\end{tabular}

575 TPC: total plate count, log CFU/g; CHL: chlorophyll, mg/g of fresh weight. CK-10C and 576 CK-4C: control samples stored at 10 and $4^{\circ}$ C; FT-10C and FT-4C: samples with film treatment and stored at 10 and $4^{\circ} \mathrm{C}$. Data shows the means \pm standard deviation. Different letters represent a significant difference within the same column and block $(p<0.05)$. 


\section{Legends of Figures}

582

583 Figure 1 DSC thermograms of PLA films: (from top to bottom) $0 \% \mathrm{TBC}, 2.5 \% \mathrm{TBC}, 5 \% \mathrm{TBC}$, 584 $7.5 \% \mathrm{TBC}, 10 \% \mathrm{TBC}, 7.5 \% \mathrm{TBC}+5 \% \mathrm{AIT}$.

585

586

Figure 2 SEM images of film cross section. A: AM PLA film; B: pure PLA film. AM PLA

587

film contained $7.5 \%$ TBC and 5\% AIT.

588

589

Figure 3 Fourier transform infrared spectra of pure PLA(A) and AM PLAfilms (B). AM PLA

590

film contained 7.5\% TBC and 5\% AIT.

591

592 Figure 4 UV-Vis absorption spectra of pure PLA film and AM PLA film. AM PLA film

593 contained $7.5 \%$ TBC and 5\% AIT.

594

595

Figure 5 Release profiles of AIT from AM PLA films at three temperatures. Error bars

596 represent the standard deviation of the means.

597

598

599

Figure 6 Picture of packaged Pakchoi with AM PLA film $(4 \times 8 \mathrm{~cm})$ on the lid of PET box (highlighted).

600 


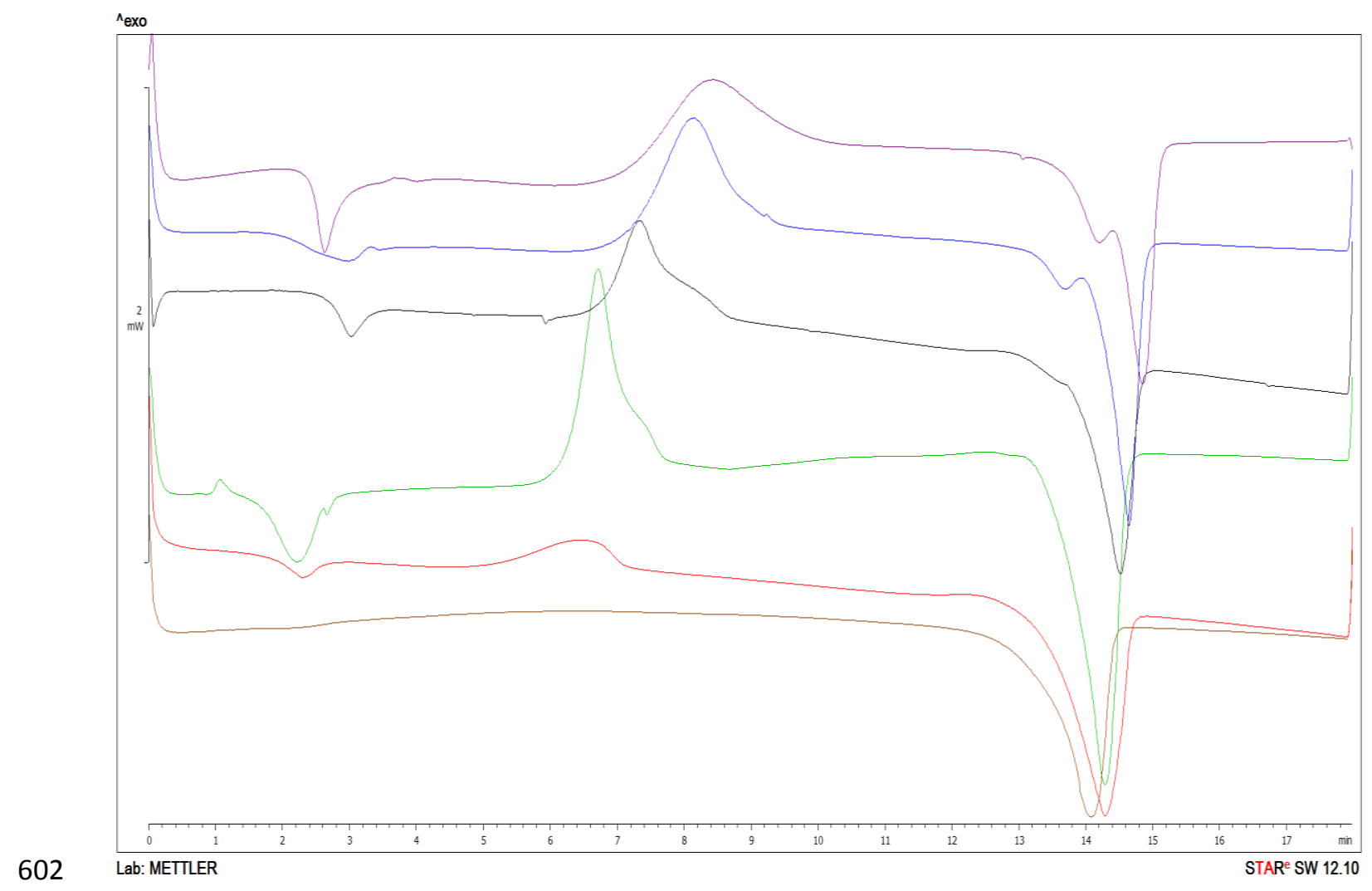

603

604 Figure 1 DSC thermograms of PLA films: (from top to bottom) 0\% TBC, $2.5 \% \mathrm{TBC}, 5 \% \mathrm{TBC}$,

605

7.5\% TBC, $10 \%$ TBC, $7.5 \% \mathrm{TBC}+5 \%$ AIT.

606 


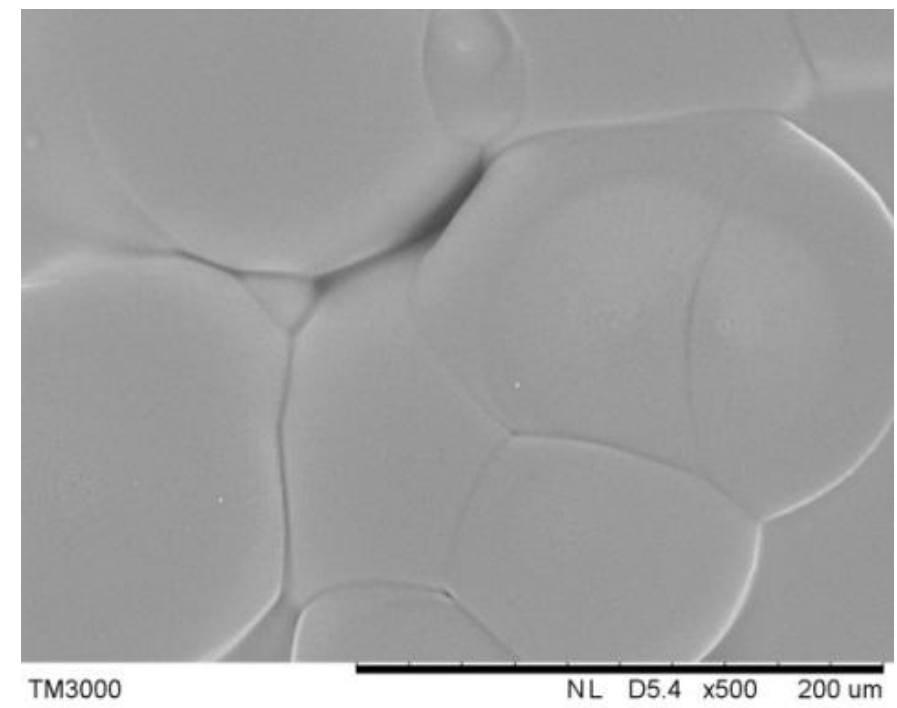

A

607

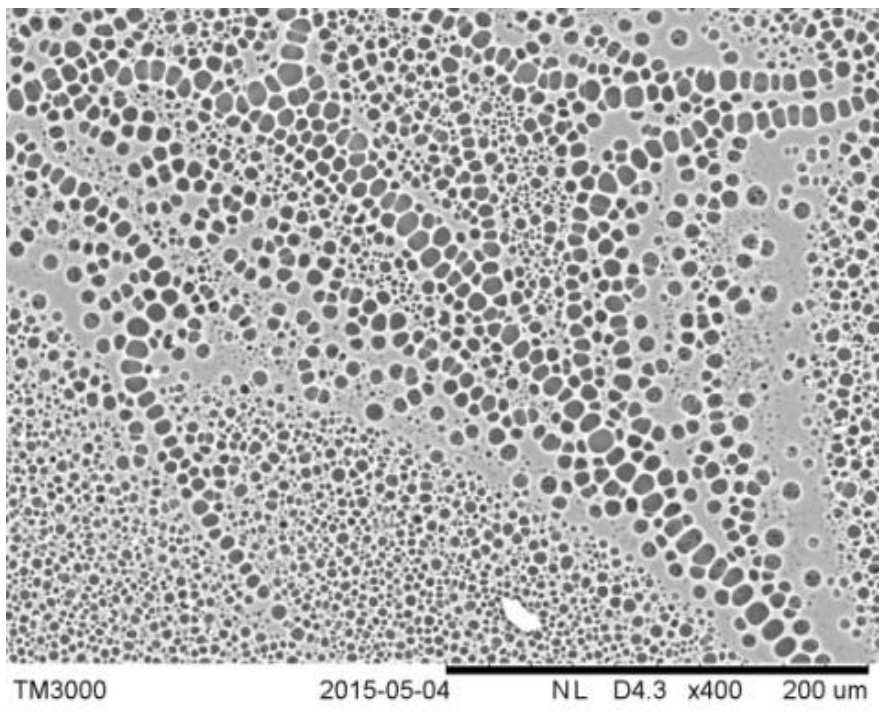

$\mathrm{B}$

608

609

610 Figure 2 SEM images of film cross section. A: AM PLA film; B: pure PLA film. AM PLA

611 film contained $7.5 \% \mathrm{TBC}$ and 5\% AIT.

612

613 


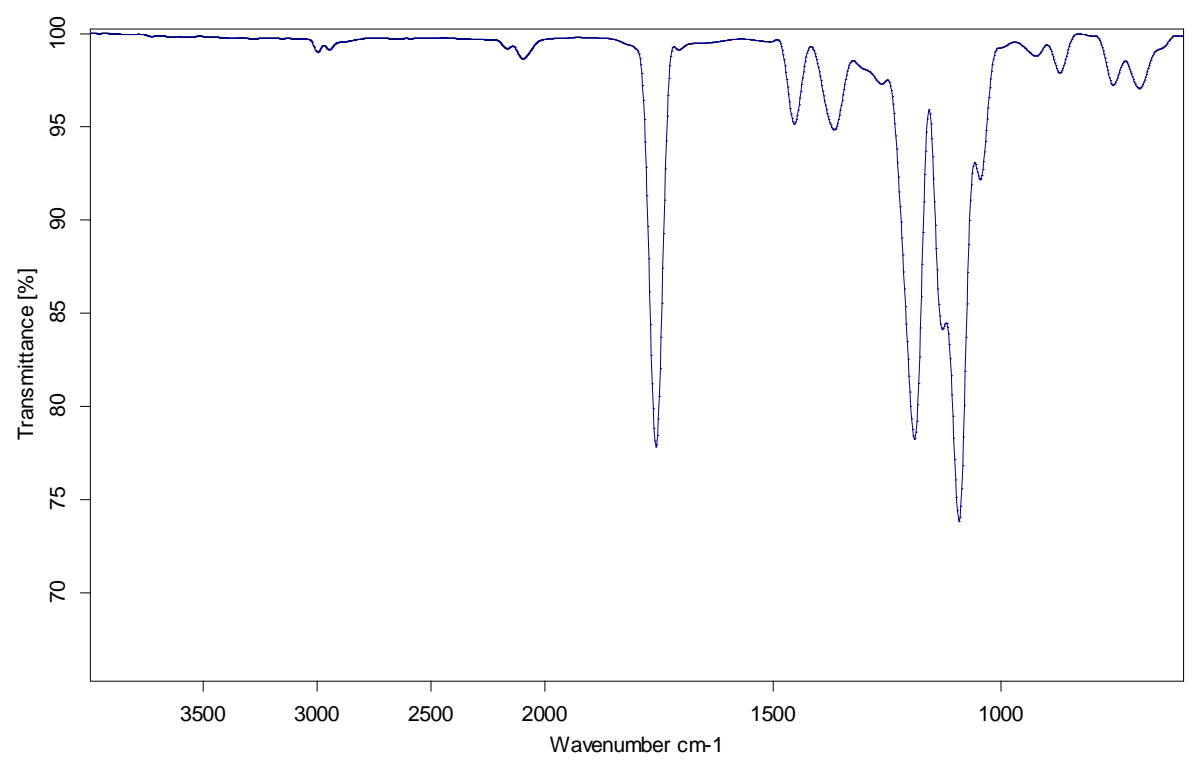

A

614

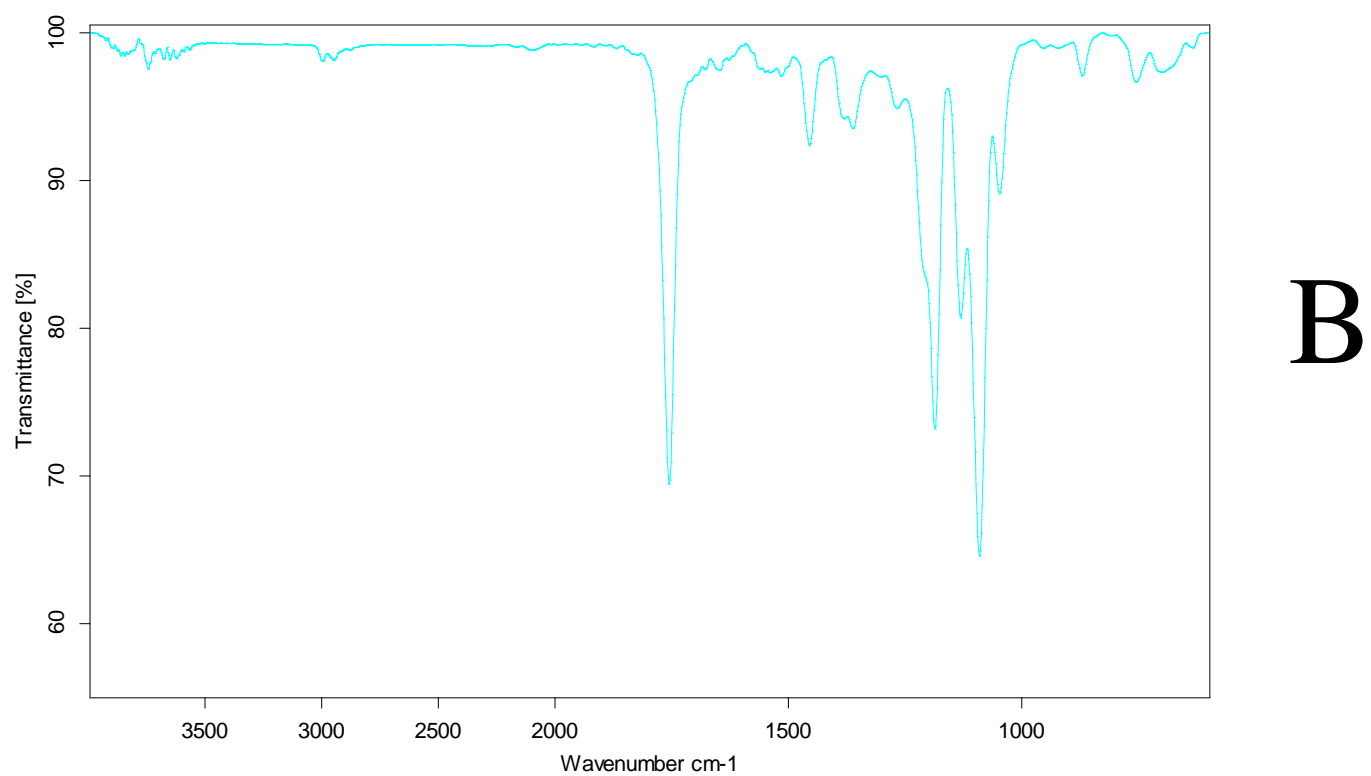

615

Wavenumber $\mathrm{cm}-1$

616 Figure 3 Fourier transform infrared spectra of pure PLA(A) and AM PLAfilms (B). AM PLA

617 film contained $7.5 \% \mathrm{TBC}$ and $5 \%$ AIT.

618 


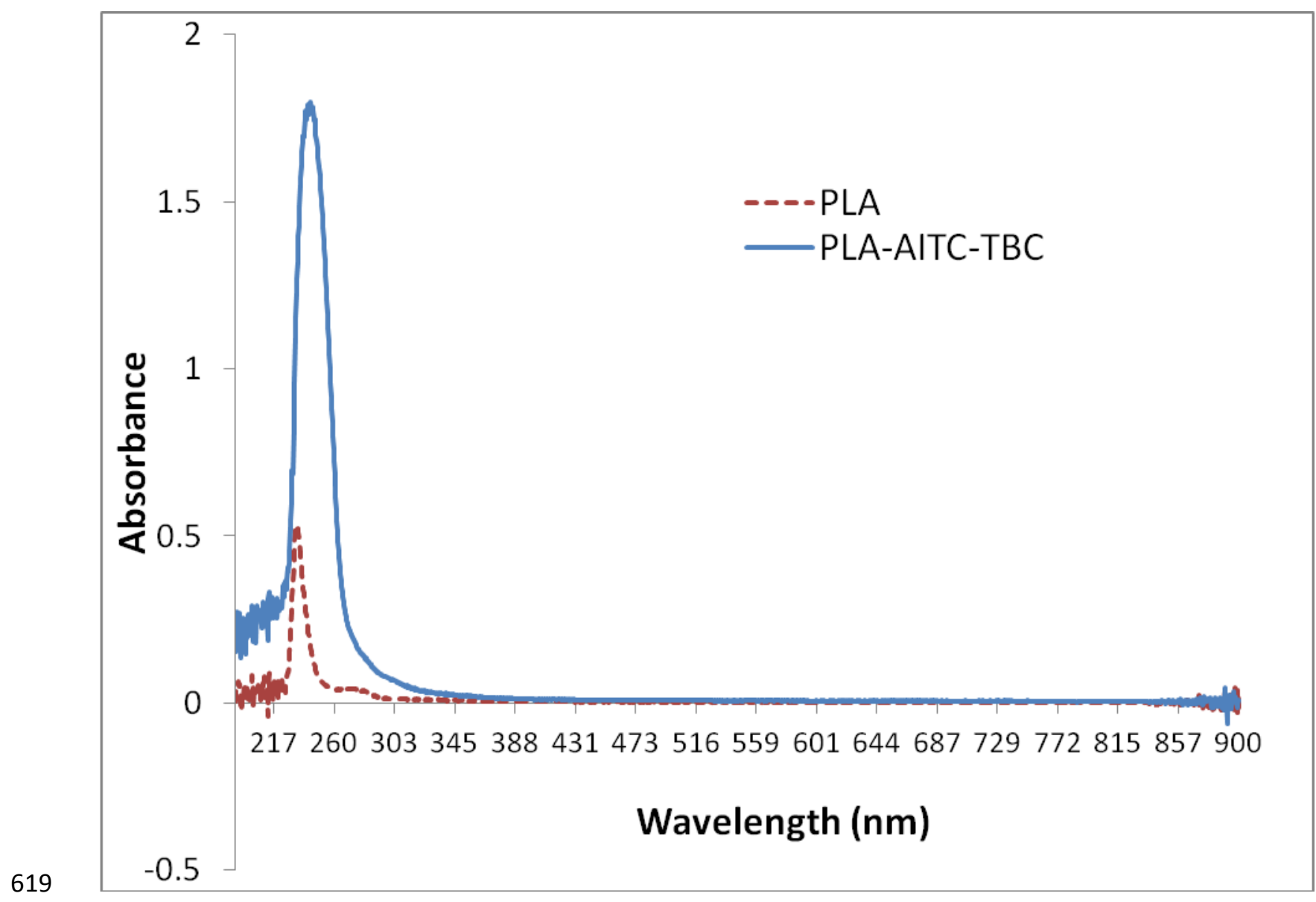

620

621 Figure 4 UV-Vis absorption spectra of pure PLA film and AM PLA film. AM PLA film 622 contained 7.5\% TBC and 5\% AIT. 


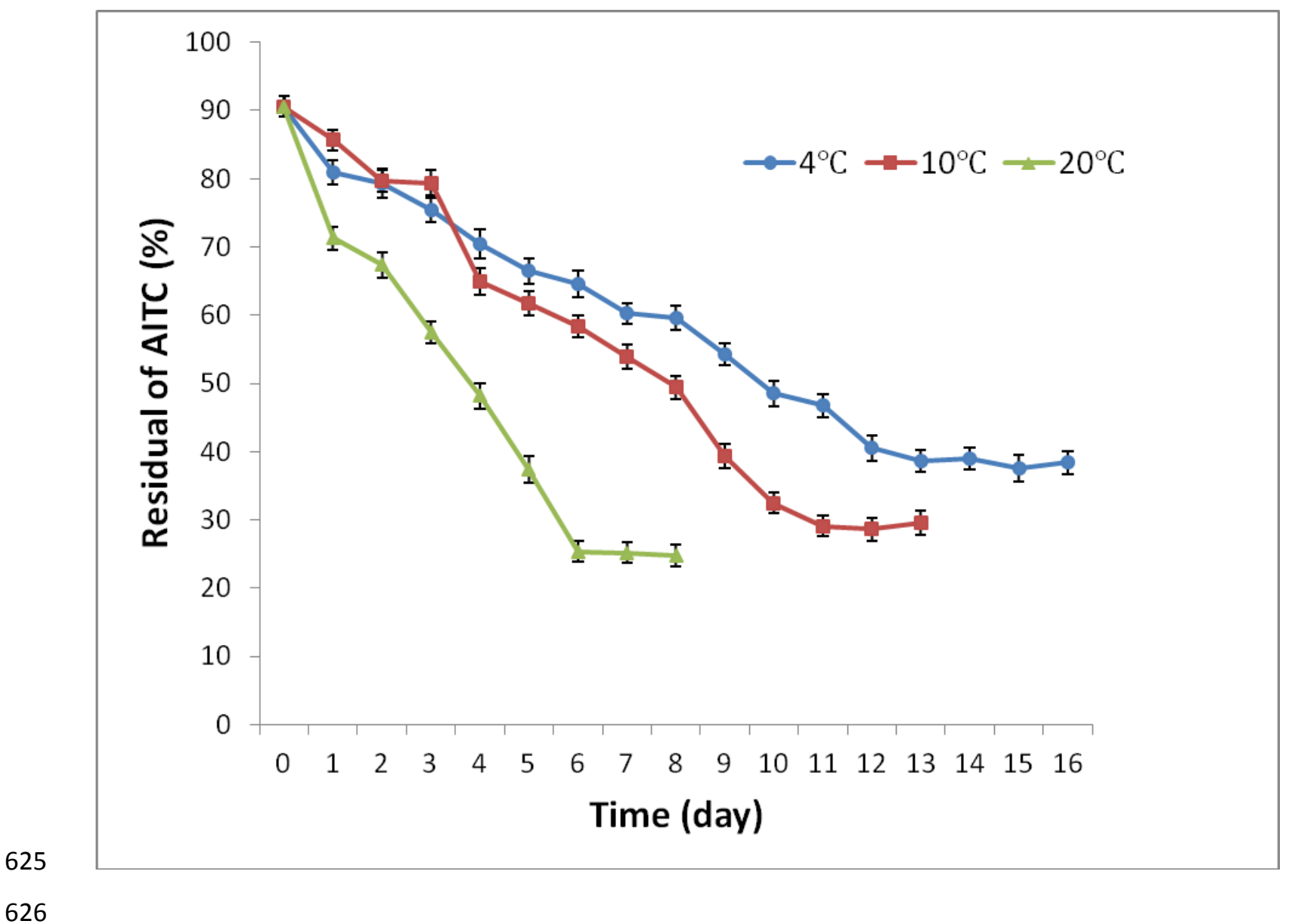

627 Figure 5 Release profiles of AIT from AM PLA films at three temperatures. Error bars 628 represent the standard deviation of the means.

629 
630

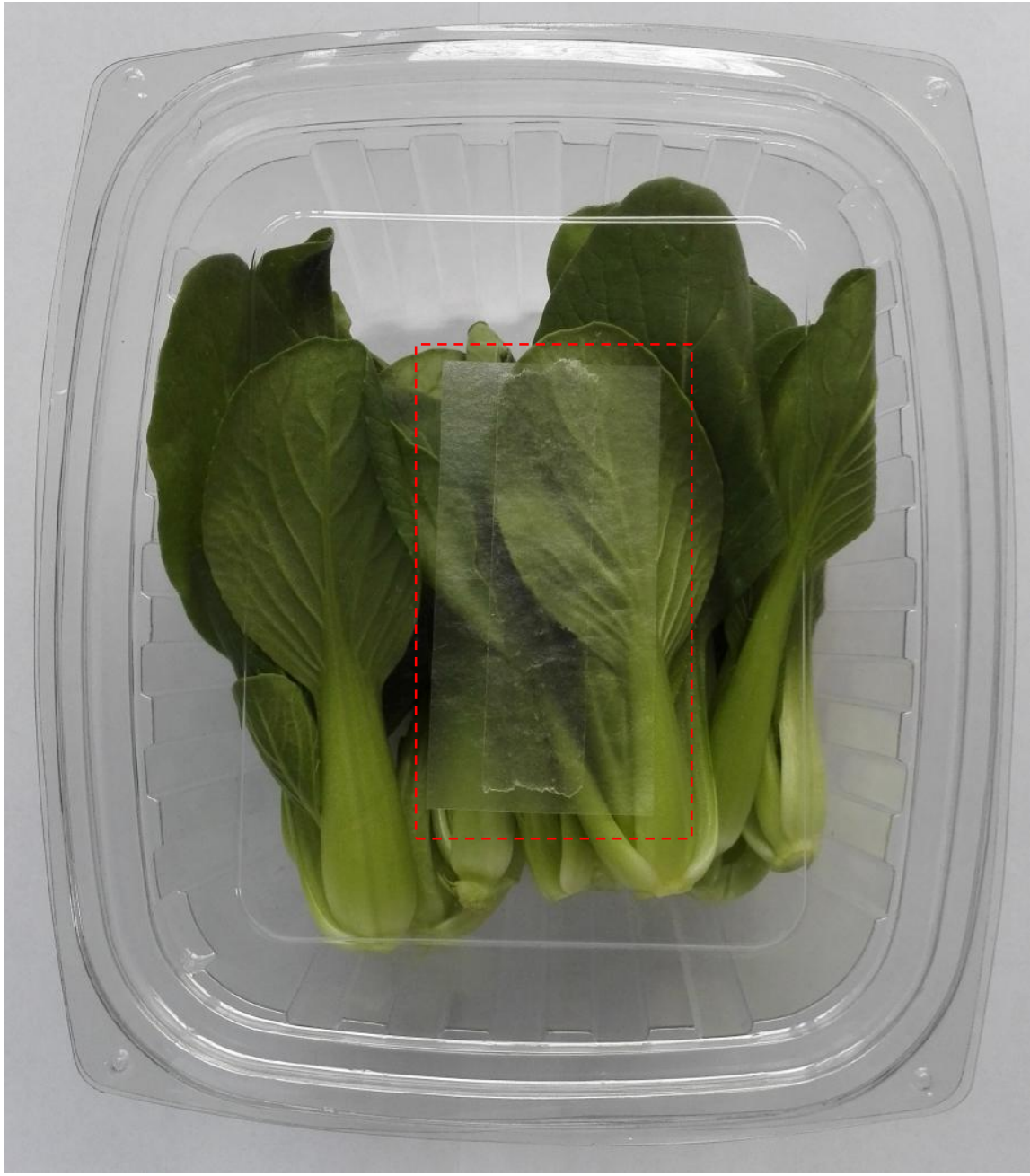

631

632 Figure 6 Picture of packaged pak choi with AM PLA film $(4 \times 8 \mathrm{~cm})$ on the lid of PET box 633 (highlighted).

634

635 